\title{
ANTROPÓNIMOS DE ETIMOLOGIA ÁRABE EN EL LEVANTE ESPAÑOL: ENSAYO METODOLÓGICO
}

Entre los actuales apellidos españoles, se conserva una serie bastante surtida, pero no excesivamente numerosa, de voces de origen árabe. Así, por ejemplo, Abda, Abdón, Abenoza, Abitar, Abenza, Abinzaga, Adalid, Aguacil, Aixa, Alacid, Albacar, Albacete, Albalat, Albarracín, Alberca, Albir, Alborch, Albuquerque, Alcacer, Alcaide, Alcalá, Alcalde, Alcántara, Alcañiz, Alcaraz, Alcázar, Alcoba, Alcolea, Alcover, Aldea, Alfageme, Alfarrás, Alférez, Alfarom, Alfocea, Algaba, Alguacil, Alhama, Alhambra, Almagro, Almansa, Almarcha, Almarza, Almazor, Almeida, Almenar, Almodóvar, Almunia, Almuzara, Alquezar, Amate, Arabí, Arrabal, Arraez, Atalaya, Aventín, etc., etc.

Todos estos apellidos pueden emparentarse, sin dificultad, con raices árabes $\mathrm{y}$, en su mayor parte, derivan de topónimos. Pueden agruparse atendiendo a su significación, a los esquemas morfológicos de los que proceden e, incluso, al ámbito geográfico en que predominan. Muchos de ellos pasaron a ser antropónimos en fechas relativamente tardias y, por tanto, no cabe creer que sus actuales poseedores tengan relación de parentela con los musulmanes españoles. Son voces que, en definitiva, ya se habían integrado, con valor propio, en el léxico de las lenguas peninsulares y asi como hoy se fundan nuevos núcleos de población con el nombre de aldea y éstas nada tienen que ver con la colonización árabe medieval, tampoco el apellido Aldea (provincias de Tarragona y Baleares) tiene que ver, en principio, con nuestros antepasados semitas. Lo mismo podrı decirse de rambla (cauce arenoso de un río) y de los Rambla (Castellón de la Plana) o de los Medina, Alcalde, Aliaraz, Aluázar, Cid, ete. Las personas así apellidadas tienen tanta sangre árabe comolos musulmanes que en el siglo XVI se llama. ban García, Ferragut, Ferrer. Castillo, Torres, Amargós, Anthonet, etc., algunos de curos nombres cncontramos citados con anterioridad al 
siglo XI ${ }^{1}$ y que se explican por la conversión en masa, al islam, de la población de la Península en el momento de la conquista.

Al lado de estos apellidos de etimología clara coexisten otros que crean alguna confusión, pues son susceptibles de recibir una doble interpretación etimológica, al igual como sucede con los topónimos. Así como entre estos Borja puede explicarse por la etimología árabe burî (torre) ${ }^{2}$ y del germánico común burgs ${ }^{3}$, así los antropónimos Ciuzmán, Gomar, Gasull, Ambrós... tienen -o pueden tener- dos etimologías distintas, la semítica y la indoeuropea. Es muy probable que los guzmanes, los gomares etc. hoy existentes tengan por epónimos a dos individuos bien diferenciados y que la adscripción al uno o al otro, al cristiano o al musulmán solo piseda hacerse, si algún día se llega a disponer de material suficiente para intentarlo, tras analizar caso por caso.

Para realizar un inventario exhaustivo de los actuales apellidos de etimología árabe sería preciso recurrir a las listas del censo electoral o a las fichas del documento nacional de identidad y tras su despoje sistemático habría que proceder a ordenarlos alfabéticamente. Este camino es prácticamente, materialmente, casi imposible de seguir, pues exigiría un trabajo ímprobo de varios años y sólo, que sepamos, se encuentra iniciado en las Baleares (Estudio General Luliano) y en Cataluña (Oficina románica de lingüistica y literatura, Biblioteca Balmes, Barcelona). En estas circunstancias no queda más remedio que recurrir a repertorios

1 Conocemos estos apellidos gracias a las nóminas (en Cataluña fogajes), realizadas en la Edad Media con motivos tiscales, a figual: en textos árabes o en los repartimientos. I.os principales trabujos sobre el tema son F. COOLER: Importancia de las fuentes árahes para conocer el cotado del vorabulario en las lenglias o dialectos españoles desde el siglo VIII al XII (Madrid, 1910); F. COI)l:RA: Apolos o sohrenombres de moros españoles en * Mélanges Martwin Décubourg" (1909), 323-334. A. MARTINEZ. PAIARES: Estudio sobre los apellidis y nombres de lagar bispanomusulmanes (Madrid, 1918, muy deficiente), F. MATEU: Nómina de los musulmanes de las montañas de Coll de Rates del reino de Valencia en 1409 , "Al-Andalus" 6 (1942), 299-335; A. MASÍA: Contribución al conocimiento del censo de la pohlación musulmana: Los moros residentes en Cataluña según los fogajes de 1491 , 1497 y 1515 , "Tamuda" 3 (1955), pp. 282.290; ). BOSCH: Dos nuevos manuscritos y papeles suelous de moriscos aragoneses, "Al-Andalus" 22 (1957), 463-470. (Vtase la bibliografia citada en este artículo). I. VERNET: El Valle del Ebro como nexo entre Oriente y Occilinte, BRABLB 23 (1950), 249-286 y M. GRAU: Contribución al estudio del estado cultural del valle del Ebro en el siglo XI y principios del XII, BRABLB 27 (1457-58), 227-272. Todos ellos han dado repertorios bastante extensos de antrupónimos de dicha región bajo la dominación musulmana.

2 C.F. M. ASIN: Contribución a la toponimia árabe de Esparia, Marid-Ciranada 1944 ; 1. VERNET: Toponimia arabiga. En "Enciclopedia lingǘstica hispinica "1 (1959), $561-578$. 1961.

: C.F. . COROMINAS: Breve diccionario etimológico de la lengua castellana, Madrid, 
de tipo comercial. Dos son los que están al alcance de la mano: 1) el Anuario (ieneral de Espiăa ${ }^{2}$ que agrupa al elemento oficial, comerciantes, industriales, etc. por provincias y dentro de éstas por partidos judiciales y municipios y 2) el Anuario Telefónico que si bien contiene muchos menos antropónimos que el anterior presenta, en cambio, la ventaja de agruparlos alfabéticamente y en bloques de mayores dimensiones: por provincias y municipios. Hemos tomado como base de nuestro trabajo el Anwario Telefónio. Año rg60.6r (citado en lo sucesivo como Anuario).

Ambos repertorios plantean inmediatamente el problema de la interpretación cuantitativa de sus datos, pues sólo inventarian a determinadas categorías de españoles: el primero, a aquéllos que desempeñan un cargo oficial o pagan una contribución; el segundo, a aquéllos que tienen teléfono. Dado que el número de teléfonos por habitante no es el mismo en todas las provincias es necesario, para comparar los valores de unas con otras, determinar previamente este valor y de aquí pasar al tanto por ciento de apellidos de etimología árabe con respecto a la población total de la provincia. El número de teléfonos por habitante se ha obtenido considerando que una columna del Anuario tiene 65 abonados y la página de 4 columnas, 260. En este número, evidentemente, se encuentran incluidos los nombres de corporaciones (ayuntamientos, diputaciones, universidades, sociedades mercantiles etc.) que no son antropóninus. Para haber sido exactos, hubiéramos debido tenerlos en cuenta y restarlos del número total para determinar exactamente el número de antropónimos del Anario. Sin embargo, un breve sondeo nos ha mostrado que su cuantía es de poca monta en comparación con el ingente número de antropónimos propiamente tales que figuran en el Anuario. La ordenación de las provincias estudiadas según el mayor o menor número de teléfonos por habitante coincide, en líneas generales, con el ordinal de las recaudaciones por el impuesto de consumos de lujo y de renta ${ }^{2}$.

1 También conocido como Bally-Baillierce Ricr. Barcelona, 1961; 4 tomos. Los datos que aporta el Diccionari catali-valencia-balcar de ALCOVER-MOL.L, muy interesantes y nutridos, no han sido tenidos en cuenta syui por registrar sólo la localización geográfica de los apellidos sin aludir a su densidad. Un buen estado de la cuestión puede verse en F. de B. MOLL: Els llinatges catalans, Palmd de Mallored, 1959.

2 La comparación la hemos hecho a base de los datos del Anvario estadistico de España. Edición manual (Madrid, 1959) y list.dio solbe la reparticioin de la renta anual en España (Bilbao, 1958). 
La selección de los apellidos se ha hecho teniendo en cuenta únicamente el paterno o primero, dado que en el Anuario falta, con relativa frecuencia, el materno. En caso de haber contado los dos, se hubiese complicado, notablemente, el trabajo estadístico. La elección de las provincias levantinas se ha hecho teniendo a la vista el excelente trabajo de Il. LAPEYRE: (cóographic de l'bspagne morisque' y su orden de lectura ha sido el siguiente: Alicante, Murcia, Almería, Castellón, Tarragona, Huesca, Lérida, Baleares y Valencia. En nuestras notas hemos prescindido de todos aquellos nombres que nos han parecido discutibles (Guzmán, Gomar, etc., pero no Gasull y derivados). A pesar de esta precaución es posible que hayamos incluido algún nombre de etimología no árabe, que esperamos que quede compensado por la exclusión de otros cuyo origen árabe es poco aparente. Debe ser así, pues el porcentaje de antropónimos de origen árabe seleccionados (882) que corresponde, por su inicial, a las distintas letras del alfabeto, se corresponde, sensiblemente, con el de topónimos seguros (986) registrados por Asín, bajo la misma inicial. Los casos de discrepancia notable se encuentran en la $M$ (topónimos $6,2 \%$ frente a $12,2 \%$ y la $A$ (topónimos $40,8 \%$ frente a $28,2 \%$ ). Pero estas diferencias pueden explicarse por la especial contextura de topónimos y antropónimos. En estos últimos, en los que frecuentemente se integra la kunya "abü", ésta sufre aféresis de a y pasa a $b$ (Abū Jaldón) Bujaldón, ete. Además la partícula filiativa $i b n, b c n$, se prefijaba muchas veces al nombre. De aquí que para comparar los porcentajes de topónimos y antropónimos haya que tomar ambas letras, la a y la $h$ a la vez. Así se obtienen valores mís parecidos (topónimos $58,3 \%$ frente a $47^{\circ} \%$ ). En cambio no accramos a explicar de modo completamente satisfactorio, la discrepancia de valores en la $\mathrm{m}^{3}$.

Al elaborar nuestro inventario hemos desglosado la capital de la provincia de ésta" y hemos contado los indivictuos con apellidos de etimología árabe en cada caso y reducido la citra así obtenida a un

1 Cf. la critica de dicha obra hecha pur I. RI:(iT.A: Ios moriscos: Estado de la cuestión y nue tas aportaciones documentales, "Saitabi" $10\left(\mathrm{i}^{1} / 6,0\right), 101-1.30$.

- Buros mismos cambios siguen experimentándove en los didectos nerárabes. Véase, como ejemplo las paginas que el Anuario dedica a las ciulades del Norte de África.

s Lina primera razón la constituye la existencia de apellidos muy difundidos (Meca. Medina...)

- Damos aqui las gracias a nuestro amigo, Prof. Sales, catedratico de estadística, con

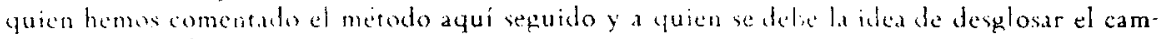
por de la ciputal. 
valor ponderado a base de multiplicar el número de apellidos por el de teléfonos por habitante. Obtenido este producto (número probable de habitantes con nombre de etimología árabe) se ha calculado su porcentaje respecto de la población total (de la capital o de la provincia). Los resultados se encuentran reunidos en el siguiente cuadro:

(a = nombre de la capital; b miles de habitantes; c... páginas del Anuario; $\mathrm{d}=260 \mathrm{c} ; \mathrm{c}-$ número de habitantes por téléfono; $\mathrm{f}$. número de apellidos de ctimología árabe registrados en el Anuario; $g=$ apellidos ponderahos; $h=$ tanto por ciento).

\begin{tabular}{|c|c|c|c|c|c|c|c|}
\hline a & b & $\mathbf{c}$ & d & e & f & $g$ & $\mathbf{h}$ \\
\hline mería & 76 & 8 & 2080 & 36,5 & 85 & 3102,5 & $4,($ \\
\hline Prov. & 28 & & 340 & 120 & 20 & & \\
\hline urcia . & 2 & 20 & 5200 & & 26 & & \\
\hline Pro & 5 & & () & & 231 & & \\
\hline icante... & & & 0 & & 8 & & \\
\hline Pro & 5 & 49 & 127 & & 32 & & \\
\hline $\operatorname{lma} . .$. & & 3 & 83 & & 06 & & \\
\hline Prov. & 29 & 18 & 4 & 63 & 19 & & 4 \\
\hline alencia.. & 5 & 128 & ) & ) & 1.386 & & , \\
\hline . & 803 & 6.3 & 16.3 & 4) & 64.3 & 31 & 3, \\
\hline astellón & 5 & 9) & 0 & $2 \cdot 2$ & 79 & 1 & 3 \\
\hline $\mathrm{D}$ & 272 & 14 & $36+0$ & 74 & 1.36 & 10172 & $\therefore, 7$ \\
\hline rago & 30 & 7 & 1820 & 21 & 27 & 5 & 1, \\
\hline $\operatorname{Pr}$ & 318 & 29 & 7.540 & 42 & 108 & 4. & 1, \\
\hline érida & & 10 & 2600 & 20 & 62 & & 2 \\
\hline & 271 & 24 & 6240 & 43 & 71 & 3081 & \\
\hline Hue & ? & 4 & 1040 & 21 & 19 & 4012 & \\
\hline & 346 & 14 & 3640 & 95,0 & 102 & 9690 & 2, \\
\hline
\end{tabular}

En el cuadro que antecede se puede observar:

1) El número de apellidos de etimología árabe aumenta, progresivamente, al ava car de norte a sur, excepto en dos provincias: Alicante y Murcia. Frente al 4,1/3,9 de Valencia presentan los valores $2,5 / 1,4$ y 2,4/2,5 respectivamente, para subir bruscamente en Almeria a $4,0 / 5,1$. Este hecho, que no esperábamos, nos ha llevado a releer el Anuario en lo que a esas provincias se refiere. Comprobado que no hubo error de contaje, hemos examinado los valores obtenidos por 
11. L.AUTENSCH ${ }^{1}$ para los topónimos y hemos visto que en la misma región se produce un descenso similar: Valencia 19,1 topónimos por cien mil habitantes, Alicante, 29,5; Murcia, 13,2; Almería, 45,7. Esta anomalía --para los antropónimos - puede tener varias explicaciones: a) Una emigración mayor a las grandes ciudades, Barcelona y Madrid en primer término, de murcianos y alicantinos; en segundo muy importante en épocas pretéritas, pero aún cercanas a nosotros-al Oranesado. Los valores numéricos de estas corrientes emigratorias hacia Barcelona han sido establecidos por MARÍA DE BOLOS y al margen de cualquier interpretación cuantitativa queda bien reflejada en las páginas del Anuario dedicadas a Barcelona, las cuales constituyen una fuente inagotable de variantes gráficas que permiten establecer las ctimologias de varios nombres. b) Una sustitución más radical de mudéjares y moriscos por poblaciones cristianas de otras regiones españolis. c) Los repobladores tenían su apellido definitivamente fijado y no lo alteraron al entrar en contacto con la toponimia local.

2) En todas estas provincias - excepto Valencia y Baleares-- el número absoluto de apellidos de etimología árabe es mayor en el campo yue en la ciudad. El fenómeno se explica por la gran densidad telefonica de Palma (1:15) y Valencia $(1: 16)$.

3) La provincia de Huesca presenta mayor número de antropónimos que ha de léridi, lo cual se corresponde bien con los porcentajes de topónimos.

Potriamos plantearnos el problema de si existe alguna relación de parentela sanguinea entre los actuales poseedores de estos apellidos y los antiguos musulmanes de la Península (árabes, bereberes, mudéjares o moriscos) que habitaron en las mismas regiones. Considerado el asunto en bleque creemos que es prácticamente imposible resolverlo, a pesar de existir alguna que otra relación numérica curiosa y en un caso, el de l. provincia de Tarragona, quizás interesante. NADAL, y (iIRALT han establecido ${ }^{3}$ que en la provincia de Tarragona quedó un núcleo de

1 Maturishe Zige im geograpbiscben Bild der iberiscben Halbinsel: I, Veber die topographusion Vamen atabiscben Ursprangs in Spanien und Portugal, (Bonn, 1960) que constituye un. reedición del artículo publicado en el mismo rítulo en "Die Eirde" 3-4 (1954), $219.2+3$ y recogido por I. VFRNFT en Teponimia...

* Ia inmigración an Barcelona en los dos altimos decentos. "Fostudios Geográficos*20, nim. 75 (1959), 209.249 con datos sumamente interesantes desde 1900.

y Vinsay metodolígico para el estudio de la población calalana de 1553 a 17 17.Fl1:31.3(19.53), 2.34.284. lintos datos han sido acogidos y aceptados por II. I.APEYRE, p. 107 y 209 
moriscos residuales de 397 familias (1.588 o 1.985 individuos según sean 4 ó 5 el núrnero de miembros de la familia). El aumento vegetativo desde 1615 hasta 1950 puede estimarse en un 3,3 ', lo cual equivale a decir que los descendientes actuales de dicho núcleo de población asciende a unas 6.000 almas. Fista cantidad es del mismo orden que la obtenida por nosotros (5.123) para el número de personas que en la actualidad tienen apellidos de etimología árabe. Estos valores tan próximos constituyen, conı hemos dicho, una simple curiosidad, puesto que para llegar a su interpretación correcta habría que establecer, caso por caso, la evolución histórico-filológica de los distintos apellidos, conocer el porcentaje de morisios con nombre romance que figuran en los fogajes, determinar las corrientes migratorias de dicha provincia y añadir al censo de ésta aquellos apellidos de origen tarraconense y eti. mología árabe que figuran en el Anuario de Barcelona. Pero a pesar de estas consideraciones, la similitud numérica parece permitir el sacar una conclusión interesante: que los 5.123 individuos tarracionenses que en la actualidad llevan apellidos de etimología árabe, representan la cifra mínima de descendientes de los moriscos de dicha región.

I. VERNET

Coeficiente calculado a base de los datos del Anuario estalistico de España... 